\title{
CERTAIN FURTHER FACTORS IN THE PHYSIOLOGY OF EUPHORIA'
}

\author{
BY GEORGE V. N. DEARBORN
}

Tufts College Medical and Dental Sehools, Boston, and Sargent Normal School, Cambridge CONTENTS

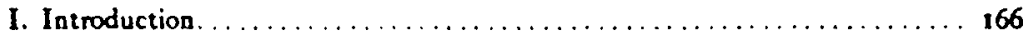

II. Ponsible Further Euphoric Factors:

A. Nutritional Influences from the Intestine $\ldots \ldots \ldots \ldots \ldots \ldots \ldots, \mathbf{1 6 9}$

B. Kinesthesia ........................... 172

C. The Epicritic Impulses........................ 175

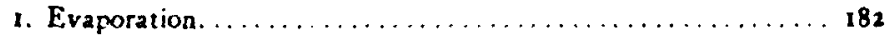

2. Oxidation $\ldots \ldots \ldots \ldots \ldots \ldots \ldots \ldots \ldots \ldots \ldots \ldots \ldots \ldots \ldots \ldots \ldots \ldots, \mathbf{1 8}_{\mathbf{3}}$

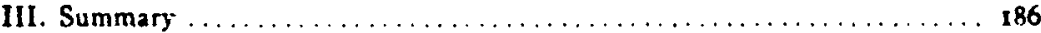

IV. References ........................... 187

\section{INTRODUCTION}

In a recent article (5) on the relations of sthenia to certain phases of education, the writer had occasion to mention, and a little more, some of the factors of physiological euphoria (experience of satisfaction or of pleasantness) as set forth, for example, by $H$. Spencer (25), Marshall (20), Max Meyer $(21,22)$, myself (9) and many others early and of late. The essence of all such discussions seems to be the ample, unimpeded, undeflected, and furthering nervous impulses from large receptive fields especially such of these as represent personal expansiveness. It is our present endeavor to make slightly more explicit certain of these receptive fields, loci of personal relation to the effective environment.

One matter of definition of terms must be understood at the outset, as all along: "euphoria" is not necessarily coextensive with happiness or even with "the experience of satisfaction or of pleasantness" for either of these may be, and of course frequently is, dependent on ideational processes

1 From the twenty-second annual meeting of the American Paychological Association at New Haven, 31 January, 1914. 
proper, in the narrow sense, that is, of conceptualization: a mere idea, a pure idea may make a man, for the time at least, happy and afford him what we might well learn to call ideational euphoria as in some degree different, especially in its occasion, from the euphoria of which we write-physiological euphoria. It should "go" without being said that in the long run the former has dependence on the latter; else, indeed, all of us more or less were poets, artists, metaphysicians, reformers, and science had no place. In choosing a home-site a large library or even a prospect sublime as the skies is not enough. Our concern in this immediate article is then with euphoria in its dynamic or physiologic relations. We shall discuss some of the bodily and environmental conditions that seem most importantly connected in and with physiologic euphoria under normally biologic circumstances, the interesting euphoria of insanity being, for the time, ignored. Advancing understanding of certain physiologic relations makes further psychologic analysis now possiblc, and provides us with more cenesthetic "mind-(?)stuff" as the receptive fields become better and better understood.

It is a traditional presumption worthy of all acceptance that the affect, the cmotional balance whether euphoric, dysphoric, or neutral represents the personal reaction when the individual is more or less well adapted to its environment, especially its organic environment. The individual as a whole and neurally has some "attitude" toward non-individual part of his experience. It is important to note that for neurology a part of this objective environment may be within the body of the individual, anywhere in short except within a nervecenter! For convenience, then, in this particular discussion, and perhaps elsewhere, we may divide a man's environment into two parts equally essential almost to his behavior and to his well-being, I, outside the skin altogether and, 2 , outside the receptors in the viscera, muscles or wherenot in the body. So far as neurility is concerned obviously these are equally environmental. (Such a consideration is only one more step in that integration of life and mind and environment which is a key-note of our day.) That in the long run and in general the affect 
represents more truly than anything else the personal reaction to environment thus broadly denoted need not be enlarged upon here. Verworn in his Yale lectures published under the title "Irritability" (26) has recently made an elaborate analysis of the bases of this interdependence and concludes, rightly and usefully it appears, that "a stimulus is any change in the vital conditions." This is a good step beyond Fechner and Du BoisReymond and in the right direction of orienting personality and its determinants.

We seek, therefore, to make a bit more definite and concrete the current notions as to the euphoric receptors as receivers of changes in the vital conditions and to suggest, if we may, the general nature of the afferent influences that determine the tonicity or strain or neurokinesis or whatever in the central and especially in the cerebral, gray. Such a discussion is in a sense and degree the homologue on the one hand of a sketch of the neurology of voluntary movement already proffered (I I) and, on the other, of the neurology of the vegetative mechanism to come as soon as the autonomic system, especially its afferent aspects, now so blind, shall have been revealed. Thus little by little behavior's neurility will be elaborated as a truly adequate "sanction of psychology."

\section{Possible Further Euphoric Factors}

It appears that three factors especially of the influences of the euphoric receptive fields may be profitably described in - somewhat new detail. Each of these is complex enough and as yet little enough understood to challenge the curiosity and the scientific constructive imagination of many investigators. The three factors noted are: $A$, nutritional and sympathetic influences from the active intestinal villi; $B$, kinesthesia; and, $C$, the epicritic impulses. Let us examine into the part each of these obvious factors takes in euphoria; it seems to be another troublesome case of estimating our income of lifesatisfaction at the source. It is clear that ideational euphoria and the ideational elements of euphoria in general arise more directly from the cortical associations, yet these latter, too, recent observations suggest, secure their animus in the environ- 
ment to some extent and largely in the innervation of expression-muscle be the view that of animism or other.

$A$. The nutritional and sympathetic influences from the intestinal villi are clearly two things and not one. The nutritional influences toward good humor, "feeling good," go to the neurones (and especially to the cortical nerve-cells?) in the portal and systematic blood-streams; while the sympathetic impulses are the little-known but certain afferent autonomic nerve-currents which experimental physiology and one's personal experience both suggest. We may dismiss these neural contributions to the cenesthesia of comfort and well-being with the above word,-but of necessity, not from choice, for it may not be doubted that these afferent impulses from the viscera have much of importance to do with the determination of moods and passions and temperaments, with, in short, all the most fundamental affective themes that underlie consciousness and behavior.

The nutritional influences toward good humor are not as yet on a basis of physiological demonstration through vivisectional experiment and chemical analysis of the blood in euphoria and in dysphoria. Such demonstration would be difficult to carry out owing largely to our necessary ignorance of the affective tone of a brute when not part of a definite emotion such as fear or love. The affect during a fast deliberately carried on for days or even a few weeks is a problem apart, and one which merits study: in some manner, much perhaps as in a bad pneumonia or other asthenic fever, the weakness here merges into a relative anesthesia in which the affective tones both ways are indistinct. But under ordinary conditions of nutrition there is undeniably, I think, a demonstrable direct relationship between absorption from the small intestine and the affective tone. The dysphoria of acute fatigue, in part certainly central, would otherwise not be so immediately relieved by a glass of hot milk or malted milk or of some variety of soup. A hungry worried man home from the office to dinner could not feel his dysphoric worries slip away so very quickly from any other influence than a direct nutritive stimulation of the central, especially cortical, nerve-cells. It is not a traditional delusion 
that fat men and boys are usually good-natured and lean women cuttingly keen and not obviously too happy. On the one hand the Esquimaux and on the other the races of southern Europe, both eaters of much fat, certainly have a higher euphoric index than the Scotchman, for example, or the thin down-East Yankee.

While the exact chemical nature of the Nissl's granules (tigroid substance, chromatophile bodies, chromatin bodies) is not definitely known as yet (owing to the minuteness of the nerve cells and the impossibility so far of separating thees bodies from the cytoplasm around them), there is general belief that this material chromatin is a complex substance essentially compounded of fat and protein in which the characteristic determinant is what the biologists term a lipoid, a "fat-like" material, phosphorized fat (Goldscheider). Austin and Sloan (1 $A$ ) and Dolley (12) have demonstrated the direct dependence of nerve-cell activity on the chromatin masses, and the quick loss of chromatin when the katabolism exceeds the anabolism. I think we may, then, deem the cerebral end of the process under discussion well established:- that the normal action of the cortical-neurones requires an abundance of circulating fat (or "lipoid"-producing carbohydrate) as well as of protein. In addition to the chromatin-masses, the myelin sheath of the medullated nerves is an adipose substance, very likely nutritive to the neurite.

So far as the competency of the circulation is concerned to keep the minute nerve-cells in immediate and constant relation with the blood-plasma (lymph), it is enough to remind the reader that a blood corpuscle passes entirely through the systematic and the pulmonary "circulations" in about thirty seconds; that the capillaries are everywhere and with walls so permeable that they exist, so to say, only for the red corpuscles; and that the protoplasm of the human cortex is about 85 per cent. water. The temporal unification then of nervecell nutrition and the portal blood (from the intestine) is surprisingly complete; an increase in the fat-content in the thoracic duct would be almost immediately used in the cortex, raising the metabolic tonus of the, nerve-cells to a better affective concomitance. 
Passing now to the mechanism and process of intestinal absorption we see in the neuro-musculo-glandular mechanism of the villi and the valvulæ conniventes a much more competent and actively adaptable apparatus than has been disclosed heretofore. In general terms the presence of muscle means the active adaptation of an organ to conditions outside itself, for example in the absorptive organs mentioned as well as in the spleen and ovary.

Whatever may be the adaptive movements of the valvulæ, the villi are the chief immediate organs of food-absorption from the intestine. There are about four million of these organs in the human. They are irregular but in general finger-shaped organs varying in length from 0.5 to 3.0 millimeters. Their combined surface area situated as they are on the valvulæ conniventes increases the absorptive area of the intestine at least an hundred fold over what it would be were the gut a smooth-walled tube instead of one partly filled at times by these organs. The villus is a complex little organ for, besides its versatile and essential wall of columnar epithelium, it consists of smooth muscle, autonomic nerves, a conspicuous central lymphatic ("lacteal"), blood-vessels, leucocytes, and connective-tissue. It would be pedantic to venture conjecture as to the exact modus operandi of such a mechanism. Fat, however, is the only alimentary principle which is mechanically conveyed from the midst of the epithelial cells (where it is apparently synthesized from the fatty acids and glycerin) to the central lymphatic. The chief function of this "lacteal," so far as known, is to receive the fat globules and to forward them into the circulation proper via the thoracic duct. Howell says (19I3): "The mechanism of absorption remains unexplained." It is, however, extremely probable that the neuromuscular mechanism of the villus has, as part of its function at least, the compression of the villus under nervous requisition for more fat from other parts of the body. On this basis the villus is understandable as in part a minute reservoir of adipose material, perhaps indeed chiefly for the greatly variable use of the nervous system, nerve-cells (chromatin) and nerve-fibers (myelin) alike. They clearly make up by their number what each lacks in size. 
We have now before us the vitals of a mechanism, receptors, adjustors, and effectors all complete, by which the nervous system may secure fatty (and protein?) nutriment suitable to its wide range of requirements in rest and activity and dynamogeny.

It may well be taken practically as an axiom for the relations of mind and body that optimum physiologic and psychologic function represents, in the long run at least, physiologic euphoria; at any rate we are basing this metabolic suggestion on this presumption, and probably without protest.

$B$. Kinesthesia is the second kind of contribution to be noted to the neurility of physiologic euphoria. The status of this, the fundamental behavior-sense, to so crudely term it, has been of late set forth by the writer both in its physiologic (7) and its efficiency aspects $(8, x)$. Suffice it then to say here that thousands of afferent impulses, strains, or influences from as many receptors in the joints, muscles, tendons, skin, and bones are continually pouring into the psychomotor centers. These represent in the ultimate analysis the environment to the personality within and, more specifically, integrate the body and the mind, furnishing to the psychomotor centers their only data by which the body may be coördinated.

From the somewhat different view which is rapidly becoming understood and accepted (like subconsciousness and the new-mind-stuff theory and the expedient continuity between protoplasm and mentality), usually denoted as the reservoiridea, kinesthesia supplies a considerable fraction of the intake of this head of neural energy. Muscle of course always, even in deepest slumber, has some tonus and always therefore, together with its mechanical fellow-tissues just mentioned, is sending floods of energy into the central nervous system from the latter's environment. This gray-reservoir idea has not as yet been universally enough accepted by psychologists; yet nothing is more certain than that in some mode it exists, and its usefulness to psychology every man may read.

The precise relationship between euphoria of the physiologic type and the quantity of this kinesthetic flood representing the body is probably not a direct relationship at all, for else 
conditions of the greatest bodily activity (short of cramp or catalepsy or general convulsions) would be those of the greatest delight (in so far as affect and not sensory pleasure). This of course is not the case in a bald and strict sense. On the other hand, the present writer believes that it is more nearly true than would be generally supposed at first glance and that the observed discrepancy can be explained by extraneous circumstances such as distraction of attention without, etc. In certain forms of general activity represented by kinesthesia to the brain, the relation of the quantity of movement to the euphoric index is obvious; in other phases of neuromuscular activity the direct correspondence cannot be directly made out.

Ribot in his latest book $(\mathbf{2 2} B)$ has set forth in a most interesting and important way the utter dependence of the subconscious aspect of mind on kinesthesia. And the neural determinants of euphoria are of course inherently subconscious. (This book of Ribot's, like his others, should not be overlooked by any one who would understand the bases of behavior, for they are as fundamental as they were prophetic in modern psychology.)

On the whole, so far as the mere amount of euphoric kinesthesia is concerned the correspondence seems certain but often vague.

In bodily activity in which the kinesthesia is intensively conscious and widespread the direct relation appears in emphatic form. This condition of intensive inhibitory consciousness we commonly designate as grace or gracefulness, and it is clearly a generalized skill. The logical limit of grace in the human active body would be in a form of exercise forever denied to man, namely flying. Swimming, skating and real (classic) dancing appear in practice as the maxima of grace, then, and these, as arranged here in an ascending series, seem to be, other things equal, conditions of physiologic euphoria.

When (to take a third case and phase) the kinesthesia is localized but all the more highly intensive and inhibitory and conscious on that account, we have a kinesthetic euphoria arising in any form of what is commonly termed skill. A sleight-of-hand performance, guiding a fret saw, engraving on 
metal or carving wood, drawing, pitching skillfully a base-ball -all such movements have an inherent pleasantness essentially distinct from the other factors which take part in the total behavior. They supply in intensity of kinesthesia what they lack in quantity of ingoing stimulation. From this kinesthesia comes in part the euphoria in general of all creative motor processes; without it not even the one-in-a-million child would ever learn to play the violin within the limits of human toleration.

Ample, unimpeded, undeflected, and furthering nervous impulses, then, from the action system seem to be an important factor in the euphoric neurility whenever the neurones are adequately nourished.

But kinesthesia has more to say in this matter, probably, than to emphasize itself! Bergsonite at least to this extent, I am convinced that in as much, in so far, as kinesthesia does, as already suggested, represent the environment to the personality, every sense owes its experience of intensity and of extensity to kinesthesia. Sensation proper has only quality it really seems, and whatever of quantity or intensity it represents in experience or in fact it derives from the spatial (bodily) aspect of our two-aspected personality. It is bodily reaction (as consciousness, what but kinesthesia?) which supplies the extensity, as well as the intensity, to sensation. Years before the French light [Bergson and $(\mathbf{2 2} B)$ ] dawned upon my physiologic ken, the absolute necessity of recognizing how inherently implicated space (and all its relation) in our personality, was made explicit in certain extravasations on voluntary movement (II). The body represents environmental space (as already defined) just as kinesthesia represents body and physiologic euphoria represents kinesthesia. In this nexus of inevitable experience only does the soul of man get its insistent purposes revealed-whether fulfilled or not, at any rate revealed; only so, then, does it reach reality and self-hood. Of this personality euphoria assuredly is an important aspect. The far-reaching meaning of this relation between space and experience has not as yet been adequately applied to the becoming science of behavior, the science of "things as they are." 
C. The third suggested factor in the euphoric cenesthesia, noted above as the epicritic impulses, is even less readily described with scientific satisfaction because, like kinesthesia, the human skin is a relatively neglected field for intensive study by the histologists and physiologists. It appears that stains more clearly differential than those now in use are needed before the anatomic basis of the epicritic influences and the many factors of this complex and important organ can be made fully known. Few save certain specialists in biology realize how complex this simple-looking mechanism really is.

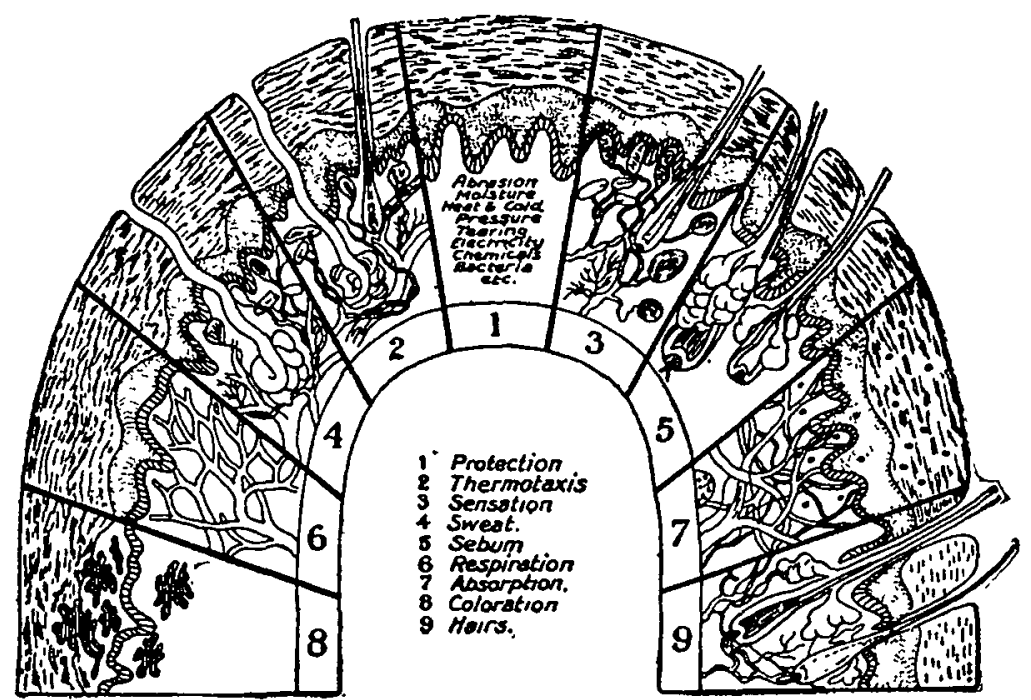

The accompanying diagram, from the writer's textbook of physiology (4), shows the various functions, but, like all other pictures at hand, fails to suggest adequately the varieties of receptors, -in this case the chief interest.

A list of the so-far-discovered more or less influential elements of the human skin would include the complex vasomotor mechanism, afferent sympathetic dendrites, the peculiarly efficient epidermis, sweat-glands, sebacious glands; Meissner's corpuscles, the terminal cylinders of Ruffini, tactile menisci, the nerve-rings of Bonnet (?), Vater-Pacinian corpuscles, free nerve-endings, heat-receptors, cold-receptors, pain-receptors, 
pleasure-receptors, perhaps tickle-receptors; arrectores pilorum muscles with their coördinating nerves.

The pioneer uncoverers of all these things (Goldscheider, von Frey, etc.) we do not for our present purpose need to refer to, but certain recent observers'and writers have emphasized the completeness of the integration of these dermal functions. Thermotactic physiology has long realized one phase of this unification, but other phases have been more recently developed by Head, Sherren, and Rivers (15, 16), and L. Hill, etc. (18), Sewall (23), Crile (3), and others. The almost heroic work of Head in this direction is a fine contribution to our knowledge of dermal cenesthesia but important as it is for psychologic physiology has less immediate use for us now than the suggestive papers of Sewall and of Crile combined with other inductions of those hygienists who are working on the science really underlying ideal ventilation.

For one thing, evidence accumulates that one large and well-nigh indispensible element of euphoria is stimulation of the skin in the way primevally natural to it, and in such a way as to allow of the free action of its combined receptive fields. The dermal receptors appear to be tuned to act euphorically, that is normally, only together, not separately nor in generic groups. The fields in short of the dermal sense organs are really receptive fields. Just as a spring wind blowing over a rich natural meadow would beneficially influence all the different kinds of herbage at once to the general enrichment of the field, making all of it glad, so, somewhat, here. The simile indeed is more than a chance choice, for it is to just this matter of moving air, outdoor air even when indoors, which I would call attention now as a basal factor in physiologic euphoria.

The empirical facts, at least, become more obvious if we state the matter in its negative aspect: We all realize that air that is "dead" (i. e., not moving) (Hill, loc. cit.); humid and too warm; humid and too cold; or lacking in oxygen; is a ready occasioner of organic dysphoria. We are here not concerned with pathological conditions, but it is relevant at least that the still blind complex we designate as chill in some way dominates the skin's euphoric balance and indeed that of the 
entire cenesthesia or sensation-fabric. Ill-defined irritations in the abdominal or thoracic viscera (especially it seems in the lungs and the intestine), and a rapidly rising body-temperature from whatever cause, almost at once can change a distinct euphoria to dysphoria at once as deep-seated and as superficial as receptors are to be found, but dominant especially of the dermal affect. It would be pedantic to claim this ill-comprehended state of chill as neurologically a lack or a set of lacks, but to suppose the normal conditions mentioned at the beginning of this paragraph lacks seems wholly justified by over increasing real knowledge of the relations of the skin to its environment. Neurally then, dead air means a lack of movement over the skin; air that is humid and too warm means a lack of stimulation by the optimum temperature and by evaporation; air that is humid and too cold means similarly a lack of the optimum temperature and a lack of dryness, evaporation so being hindered with its own important neural lack; lack of oxygen in the air, whether from its general chemical composition or from its utter deadness next to the skin, means an obvious lack of receptorial stimulation that we shall briefly consider anon. The whole trend of recent opinion, notably Sherrington's (24), is to suggest how minute, both qualitatively and quantitatively, is the adaptation under different circumstances of the receptors, especially those of the cenesthesia. Indeed Sherrington's conjectures along this path have opened a first way for useful working hypothesis on which to proceed as to the viatility of the spinal gray. Lack of movement, optimum temperature, dryness, and oxygen certainly mean lack of stimuli for very numerous receptors and a consequent lowering of the cenesthetic tide. Neurologically they seem to represent the absence or reduction of multitudes of neurokinetic contributions to the tonus of the areas of the cerebral gray, and therefore a diminution of the environmental energy representing conscious well-being. The "head" or pressure in the dynamic "reservoir" is lowered or alienated or opposed and normal euphoria thwarted.

The careful tuning, so to say, of the many and many kinds of receptors, is a matter worthy of extended research in 
the laboratories. It has been already virtually discussed to a slight extent in descriptions of the heat- and cold-sensations and in the conjectures as to their continuity or discreteness, etc. Indeed these particular receptors show what I have called tuning in an especially clear way. Evidence accumulates, however, that other sense-organs, those of oxidation, of evaporation, of tickle perhaps or of touch, may be in like manner if not in like degree relative to extraneous conditions andtunable. It must be remembered that the dermal senses, like smell, in the human are distinctly decadent senses (save in the fingertips, tongue, etc.), because so unnaturally (from a biologic standpoint) protected from wind and cold and sleet and storm, from especially perhaps the oxidation, local and reflex, for which these environmental modes of energy stand in the central nervous system. The conscious aspects of these receptors have apparently degenerated in the centuries that have gone, but the neural influence, especially in so fundamental a relation as that of the algodonic balance, remains unchanged.

Says Ellis (13) "The hygienic value of nakedness is indicated by the robust health of the savages throughout the world who go naked. The vigor of the Irish, also, has been connected with the fact that (as Fynes Moryson's Itinerary shows) both sexes, even among persons of high social class, were accustomed to go naked except for a mantle, especially in more remote parts of the country, as late as the seventeenth century. Wherever primitive races abandon nakedness for clothing, at once the tendency to disease, mortality, and degeneracy notably increases, though it must be remembered that the use of clothing is commonly accompanied by the introduction of other bad habits. 'Nakedness is the only condition universal among vigorous and healthy savages; at every other point perhaps they differ,' remarks Frederick Boyle in a paper ('Savages and Clothes,' Monthly Review, Sept., 1905), in which he brings together much evidence concerning the hygienic advantages of the natural human state in which man is 'all face." "Of these 'hygienic advantages' euphoria certainly takes no small part. Says Sewall (23): "It is through the genius of the moving air of the open that the temperature 
nerves find their most salutary stimulus and induce metabolisms characteristic of highest machine efficiency in the body. The physiologic difference between 'open' and 'closed' air depends partly or wholly on differences in the stimulation of the temperature nerves of the skin under the two conditions. The environment of the open air is conducive to an esthetic state that should not be ignored as an aid to healthy living." Indolence has been preponderatingly active among the savages of the tropics, but who can doubt that herein is one of the factors in the predominance of the man and the woman in the earth's temperate zones where the air is cool and stimulating, helping to make them happy as well as healthy,-closely related states.

A biological consideration is worth suggesting: The skin was the primeval receptive field in the phylogeny as still in the earliest months of the ontogeny, so that subconsciousness relates gentle stimulation, especially of optimum temperature, gentle friction in particular, to euphoric states. The reader does not need to be reminded that every known animal of sufficient evolutionary grade acts as if it enjoyed gentle massage of its skin. Closely related is sexual "contrectation" (Moll) which explains the seductiveness of the caress in its relation to the euphoria of being loved-the psychophysiology of which the writer has recently developed for the School of Eugenics.

The matter of the pleasantness arising from the movement of the environmental air even when a human body is clothed as is customary in English laboratories is vividly illustrated by Hill (18): Eight men were confined in three cubic meters of space; the temperature was $87^{\circ} \mathrm{F}$, the content of carbondioxide 5.26 per cent., and of oxygen 15.1 per cent. "The discomfort felt was great, all were wet with sweat, and the skin of all was flushed. The talking and laughing of the occupants had gradually become less and then wholly ceased [dysphoria]. On starting up the electric fans the relief was immediate and very great," (euphoria) in spite of the rising temperature. No headaches followed or other after-effects. In another experiment carbon dioxide up to 2 per cent. was forced into the box unknown to the eight subjects without being noticed at all by them. Most of us have had essentially 
similar experiences on sultry July days when a breeze has suddenly sprung up. The pleasantness then is a very real and physiological experience.

Professor Wm. G. Anderson, of Yale, has recently published ( 1 ) the report of a virtual repetition of Hill's work (18), and is inclined to conclude that a great increase in the proportion of carbon dioxide (from 20,000 to 30,000 per cent. above the outdoor normal of about three parts per ten thousand) is an important feature in the causation of the distressing features of a lack of ventilation. How could it be otherwise? The subjective reports of conditions as experienced or felt suggest that the feeling of dyspnea is distinct from that arising in the skin, for the starting of the fans in the close chamber afforded relief but the mild feeling of suffocation was not lessened.

One subject (a medical sophomore) reports "slight headache relieved by the fan"; another: "feeling of warmth and perspiration which was relieved by the fan;" another: "fan turned on, felt cooler and headache disappeared;" another: "discomfort, which was slightly relieved after the fan started"; another subject, the experimenter, "No symptoms except slight dyspnea [but] fan relieves the feeling of heat and wetness, but not dyspnea. After these tests a slight sore throat."

In another experiment with temperature of $83^{\circ} \mathrm{F}$, relative humidity 43 , carbon dioxide 8 . Io per cent., despite the starting of the fans which "relieved the closeness and warmth," (ten adults were in the cabinet) the suffering from the dyspnea persisted: "the sense of oppression was such that the women felt as if 'they should scream or faint' and the men were quite ready to force open the doors." For our psychologic purpose, the subjective reports of the subjects in this part of the work are perhaps worth reporting:

Dr. R.-"Dyspnea, slight headache, relicf from heat when the air was agitated but no relief from dyspnea; no permanent bad after effects."

Dr. M.- "A very slight headache while in the room and for 30 minutes after, but normal the following day."

Dr. H. L. A.- "At the end of thirty minutes very much depressed, felt weak, dyspnea, headache both sides, parietal, felt crowded, mental depression. When all left the cabinet I experienced mental and physical relief. Headache lasted threequarters of an hour." 
Miss P.- "Dyspnea, headache, depression, suffered with coldness and had slight chills for half an hour after leaving the cabinet. All right in the evening and next day."

Dr. B.- "First noticed warmth, then dyspnea and flushing of the face, throbbing of the temple arteries later, distress in epigastrium, headache which became worse on leaving the room and lasted all day. Also slight dizziness and slight mental impairment."

Dr. H.- "Frontal headache, flushed face, some perspiration, symptoms of a cold increased. Following day no bad results in evidence."

Dr. S.- "Perspiration profuse while in the cabinet, chilly afterwards, dyspnea after about five minutes, sick in the stomach, headache, micturition frequent for four hours. All rest of the day, evening and night head felt full, could not use microscope. Felt well next day when out doors but 'stuffish' in the laboratory."

Miss D.- "Had chills and other mental and physical disturbances similar to those mentioned by Miss P."

Dr.W. G. A.- "After leaving the cabinet there was severe pain in the head, temple and eyes. Some difficulty in seeing and a very evident uneasiness. Walked home, felt nervous. Ate usual light lunch. Attacked by dizziness at 1.15 p. m. (The blind headache of my boyhood.) Treated these symptoms and reported at Medical School at 2 p. m. Could not see the figures on the gas apparatus. No after headache but a heavy feeling. Vision normal at 2.30, no return of blindness, but the aftet effects of poisoning were present until $9.15 \mathrm{p} . \mathrm{m}$.

"When fatigued one particular tooth aches, and certain muscles twitch-biceps, deltoid, etc.-but on this occasion the flexor pollicis twitched for ten minutes and the molar ached or was sensitive for three hours.

"When poisoned by digestive toxics I have blind headaches. When fatigued by overwork I am apprehensive and feel that much is to be accomplished that is not done. The $\mathrm{CO}_{2}$ (?) produced this state of mind. In other words, fatigue of mind and body and $\mathrm{CO}_{2}$ poisoning affect me alike. There was no rise of temperature and no chill. There is some slight nose-bleeding." (This subject was the experimenter.)

Professor Anderson's remark that "fatigue of mind and body and $\mathrm{CO}_{2}$ poisoning affect me alike" is interesting especially in the light of Verworn's theory of fatigue (26) as essentially a suboxidation, for there is much evidence to indicate that carbon dioxide is less poisonous to man than the lack of oxygen is depressive and fatiguing. On the whole, seen broadly, Anderson's work seems to corroborate Hill's conclusions if we construe, as is needful, lack of oxygen in place of excess of carbon dioxide. In any event, Hill's findings as to the great relief in the dysphoria afforded by atmospheric movement are upheld, and no one could expect that anything at all would long compensate an organism, especially one as psychophysically complex as man's, for a deficiency of this inevitable factor of our mortal environment, oxygen. 
The fact seems to be, then, in general, that more or less regardless of the composition, temperature, humidity, etc., dead air against the skin tends to be dysphoric in action; while air moving over the skin is one of the most important of all the factors of euphoric stimulation and of sthenic activity. So far as this mental aspect is concerned the temperature of the air, however, seems to be a determining quality, in the sense at least that air (or water) too cold or too hot turns the balance to dysphoria (chilliness or sultriness). Because in part of its fundamental importance in ventilation (see (6)) and in the science and art of clothing and in the hygiene of the bath, the dermal problem suggested here is not only a matter of large practical importance, helping to fix the conditions of our greatest practical health and efficiency, but it is also a nice enigma for solution by psychology-for the crux of the problem is psychological; to be carried out, as usual, physiologically. The present writer makes no present pretenses certainly to have solved the problem, and it is with much diffidence (sic) that he ventures the following suggestions. Real solution waits on histology or on a new kind of histologic physiology, whereupon psychology may determine the euphoric relationships.

Of the several possible explanations of the empirical facts now roughly stated above, two, taken together or possibly separately, seem the most likely in view of what is now known about the skin and its stimuli. One of these is a process of evaporation and the other oxidation. One or both of these neurally physiochemic functions seem to stand for the necessary floods of (euphoric) neurokinesis into the central nervous system.

The evaporation of the sweat poured out into the epidermis, a sponge-like reticulum of keratin, is well known to be the chief means to the regulation of temperature, in homotherms. The average daily amount appears to be about I,500 c.c. but a group of glass-makers observed by McElroy had an average secretion of about 25,000 c.c. in the course of a nine-hour "day"; occasionally (owing to some bulbar trouble?) the production stopped, whereupon the man would become ill, 
have to cease work, and would be revived by the active efforts of his fellow-workers. These facts are cited because they show the very great and useful adaptability of the sweating function and the extreme dysphoria of its cessation. Sultry and "muggy" weather shows us the same thing of course, unless we be exercising actively when in part the freer evaporation reduces the dysphoria even to its opposite, to a tone of pleasantness. One sees, for example, the students in a summer school of physical education enjoying with a real euphoria vigorous exercise with the gymnasium-temperature in the nineties.

It is not then by any means obvious that the "cold-spots" (we know nothing as yet of the actual receptors) are the sole forwarders of the streams of energy that represent euphoria due to dermal or sudoral evaporation. Several other of the receptors noted above may be concerned in this process of adaptation of the individual to his environment through energized tones of pleasantness and of unpleasantness. Here the case is homolgous, biologically speaking, to two sensations, whose end-organs are no better known, pain and pleasure.

The second process which appears to actuate dermal receptors so as to effect an euphoric tone in the individual's consciousness (not to say. in his subconsciousness) is oxidation, one of metabolism's foundation-stones. Experiments done long ago seemed to show that so far as the body's respiration is concerned only about 0.5 per cent. occurs directly through the skin. But this small fraction shows that oxidative processes do ociur in the skin. When one considers the minuteness of the various dermal receptors and their possibilities of actuation by the "circumambient air," together with physiologic data immediately to be noted, the reasonableness of supposing dermal oxidation to be a factor of euphoria is readily admitted. Bohr (2) showed that ventilation of the blood in the lungs is probably a reflex process of active secretion by the alveolar epithelium. Y. Henderson ( 17 ) on the other hand, while admitting the oxidative secretion, supposes that the depression of "mugginess" comes from the kolionic inhibition of this secretion in the lungs. The receptors of this oxidation reflex it is possible, or rather more, are in the skin, and may be found to be one of 
the varieties of end-organ mentioned considerably above. Lusk (19) showed by experiments in which men were emersed in water at $10^{\circ} \mathrm{C}$. for from seven or eight to twelve minutes that the metabolism increased 181 per cent.-and respiration is always the metabolic index. The experimenter ascribed the increase to the men's shivering, but it seems possible at least in the light of Bohr's work that the increased activity of alveolar secretion of oxygen into the blood may have something to do with the heightened oxidation.

This supposition seems strengthened by late work of Verworn (26) which demonstrates, among other important things, the immediate dependence of the action of the nervous system on oxygen,- - an extension of his much earlier proof that ameba stops flowing in about an hour when oxygen is removed from its environment. Without idle speculation as to the affective tones of ameba (!), it is fairly rational to presume that some or all of the delicately complex receptors in the human skin, close to the air as they are, may have their activity and their consequent streams of neurokinesis increased by exposure to moving air as contrasted with air that is dead. It is my present hypothesis, then, that moving air in some way has a tonic action on the afferent influences from the skin by stimulation of whichever receptors in that very complex receptive field are tuned to this mode of energy. The mere presence of oxygen is not enough for a normal euphoria-it actuates, perhaps by way of the pulmonary epithelium, only when coming as a moving force (with friction perhaps) against or over the skin. If, however, friction be really an element in dermal cenesthesia, it is probably not the gross mechanic friction one is apt to think of first, but rather a subtle sort of physiologic friction, so to say, adapted to the extreme delicacy of the organic instruments so abundant in the human skin. On the other hand, the mysterious highly euphoric stimulation of a gale of wind when not outside the optimum range of temperature (as in the Nova Scotian summer-land in September) is known to all, and this implies that gross friction, friction in the ordinary physical sense of the term, may be also a factor in the experienced product. Massage and the caress seem to possibly imply the same thing. 
If such be elements in the centripetal cenesthesia related to euphoria, we logically should seek to discern what becomes of the various neural influences as they enter the brain. This we cannot do as yet with perfect confidence in any further detail than has been already set forth, e. g., in (5). The affective tones appear to be somehow related to the thalamus and to the great cortex especially its upper "layers" perhaps. Southard seems to suggest that there is evidence that the parietal region has especial concomitance with consciousness -a tendency to localization which seems to the present writer exceptional and in the long run misleading.

Here as everywhere in such work we are almost blocked from continuing upward and outward into the cortex by our black ignorance as to the nature of the neuronal energy, neurility. Still, here and there a step ahead is taken. For example the all-or-none principle (first applied to hearts, then by Lucas to voluntary muscle), need apparently be thought of as a law of action of the neurones also; any stimulus which actuates a neurone at all actuates it to its physiologic limit and in all its parts. This principle, if real for the nervous system, brings us willy nilly back again to the old familiar but still elusive synapse-the all-powerful but mythical genius which every rubber of the lamp may command at will. The process of central association concomitant to euphoria, however, remains unguessed, for the interpretation of the synapse-concept in structural terms of the material neurones is as various as its interpreters. None the less, work along the lines travelled by Sherrington, James, M. Meyer, Thorndike, Parmelee, Hollingworth, and the rest can hardly fail to lead us aright, late or soon. At present we seem capable of discussing to advantage only some phases of the afferent circuits concerned -and these, as is obvious, only with uncertain and halting tongue. This then is one opinion: that there are definite affective innervations not yet mapped out, because of the complexities and our crude and ancient methods, tied to tradition. Another opinion has already been hinted at in our introductory sentences: It may be idle to seek viatility in Morat's sense of this useful term simply because, so far as euphoria and 
dysphoria are concerned, there isn't any. Viatility, the determination of separate routes, may be confined to the "final common paths" of the attention-line (10) whether motor or ideomotor. From this position euphoria is determined (omen absit!) by an abundance of neurokinensis entering the gray fabric and by its flooding in normal amplitude and perhaps in every part the central nervous system, filling it full of happy energy.

\section{SUmmary}

1. The basal feeling-tones (euphoria and dysphoria) so far as physiological, are more or less "determined" by the environment of the receptors, euphoria representing the personal reaction when more or less perfectly adapted to its environment.

2. Three factors not yet adequately considered, contributory to the euphoric cenesthesia, appear: $A$, nutritional and sympathetic influences from the active intestinal villi; $B$, kinesthesia proper; and, $C$, the epicritic (dermal) impulses.

3. The $4,000,000$ villi of the intestine, rich in smooth muscle and sympathetic nerves as well as in epithelium, probably adapt the blood's content of the nutritive lipoids and proteins to the varying immediate needs of the nerve-cells, and may besides send inward sympathetic influences which, fusing, possibly in the brain, become euphoric.

4. The tonus and the active contraction of the voluntary musculature (by way of the articular, muscular, tendinous, osseous, and dermal receptive fields) make variable but essential contributions to the dynamic "reservoir" of the central nervous system.

Moreover (Bergson) kinesthesia probably adds much of euphoric trend to both the intensity-and the extensity-aspects of all the senses.

5. The integrated epicritic impulses (from the skin and mucosæ) appear to have predominance in human physiologic euphoria, two possible means of stimulation being evaporation and oxidation.

A list of the more or less influential elements of the skin would include the complex vasomotor mechanism; the arrec- 
tores pilorum muscles; afferent sympathetic dendrites, the peculiarly efficient epidermis, sweat glands, sebacious glands; Meissner's corpuscles, the terminal cylinders of Ruffini, tactile menisci, the nerve-rings of Bonnet (?), Vater-Pacinian corpuscles, free nerve-endings, heat-receptors, cold receptors, pain-receptors, pleasure-receptors, and possibly tickle-receptors.

6. Air that is dead (i.e., not moving); humid and too warm; humid and too cold; or lacking in oxygen, is a chief occasion of organic dysphoria. Physiologically these conditions are lacks, -lack of movement over the skin, lack of the optimum temperature, lack of dryness (evaporation so being lessened), and lack of dermal oxygen, possible reflex determinant in part of pulmonary respiration.

As regards neural dynamics, these lacks may be deemed productive of deficiencies in the cenesthetic streams (or stresses, strains, and shears) which support the cerebral neurokinesis ("reservoir")-absence of normal stimulation from the environment.

7. Adopting for the nervous system, as we must, the all-ornone principle, the actual neurology of the euphoric and sthenic balance becomes an interpretation of the synaptic relations in the body's action-system; or, better, an idea of inundation of the central nervous system by euphoric energy.

8. Physiologic euphoria is, then, more or less determined by ample and unimpeded and undeflected neurokinensis flooding the neural gray from the kinesthetic receptors and from whichever dermal receptors represent the influence of the moving air of optimum temperature over the body whenever the cerebral neurones are not short of their lipoidal protein food.

This unimpeded flood of ample neurokinesis is the condition for a high sthenia capable of actuating or inhibiting vigorously a rapid succession of motor paths.

\section{ReFERENCES}

I. Anderson, W. G. On the agitation of Air Rich in Carbon Dioxide. Medical Times, Jan., 1914.

1A. Austin, J. B., and Sloan, H. G. Phylogenetic Association in Relation to Certain Medical Problems. Cleoeland Med. Jour., X., I, Jan., 1911, 2-10.

2. Bör. Skand. Arch, Physiol., XXII., 1909, p. 228. 
3. Crule, G. W. Phylogenetic Association in Relation to Certain Medical Problems, Boston Med. and Surg. Jour., CLXIII., 1910, p. 893.

4. Dearborn, G. V. N. A Text-Book of Human Physiology, Philadelphia and New York, 1908, p. 312.

5. - The Sthenic Index in Education. Pedagogical Seminary, XIX., 2, 1912, 166-185.

6. - Certain Physiologic Aspects of School Hygiene. Education, XXXI., I, September, 19 ro.

7. - A Contribution to the Physiology of Kinesthesia. Jour. für Psychol. und Neurol., XX., 1 and 2, 1913, Illstd., 62-73.

8. - Kinesthesia and the Intelligent Will, Am. Jour. Psychol., XXIV., 2, Apr., 1913, Illstd., 204-255.

9. - The Emotion of Joy. Mon. Sup. No. 9, Psychol. Rev., April, 1899.

10. - Attention. Am. Phys. Educ. Reo., XV., 1910, XVI., 1911.

II. - Notes on the Neurology of Voluntary Movement. Med. Record, 81, 20, 18 May, 1912, 927-939.

12. Dolley, D. H. The Pathological Cytology of Surgical Shock, Jour. Med. Resrch., XX., N. S., XV., 1909, 275-295.

12A. Douglas, C. G. and Haldane, J. S. The Causes of Absotption of Oxygen by the Lungs. Jour. Physiol., XLIV., 1912, pp. 305-354.

13. Ellis, H. Sex in Relation to Soctety. Philadelphia, 1911, p. 105.

14. Goldscheider. Gesammelte Abbildgn., I, I898.

15. Head, H., Rivers, W. H. R., and Sherren, J. The Afferent Nervous System from a New Aspect. Brain, XXVIII., 1905, 99-II5.

16. Head, H., and Sherren, J. A Human Experiment in Nerve-Division. Brain, XXXI., 1908, 324-450.

17. Henderson, Y. The Unknown Factors in the Ill Effects of Bad Ventilation. Trans. Fifteenth Intntal. Cong. Hyg. and Demog., II., 1913, p. 622-628.

18. Hill, L., Howlands, R. A., ANd Walker, H. B. The Relative Influence of the Heat and Chemical Impurity of Close Air (preliminary note). Jour. Physiol., XLI., Procs., p. iii., December, 1910.

18A. Новноuse, L. T. Deoclopment and Purpose. London, 1913.

18B. - Mind in Evolution. London, I90I.

19. Lusk, G. A Method of Removing Glycogen from the Human Subject. Am. Jour. Physiol., XXVII., 1910, p. xxii.

20. Marshall, H. R. Pain, Pleasure, and Esthetics, London, 1894.

21. Meyer, M. The Nervous Correlates of Pleasantness and Unpleasantness. Psychol. Rev., XV, 1908, p. 306.

22. - The Fundamental Laws of Human Behavior. Boston, 1911.

22A. Prince, Morton. The Unconscious, New York, 1914.

22B. Riвot, Tr. La Vie Inconsciente et les Mouvements. Paris, 1914.

23. Sewall, H. On What do the Hygienic and Thereapeutic Virtues of the Open Air Depend? Jour. Am. Med. Assn., LVIII., 3, 20 January, 1912, 174.

24. Sherrincton, C. S. The Integrative Action of the Neroous System. New York, 1906.

25. Spencer, H. Principles of Psychology, 16th edn., New York, 1869.

25A. Testut, L. Traite d'A natomie Humaine. Paris, I9I I, tome III., pp. 287-364.

26. Verworn, M. Irritability. New Haven, 1913. 